\title{
INTERCAMBIO DE CONOCIMIENTOS CIENTÍFICOS Y LEGOS: UN DIÁLOGO URGENTE PARA COMPRENDER Y ACTUAR ANTE LA DIABETES
}

\section{Exchange Between Scientific and Lay Knowledges: AN URgent Dialogue for the Understanding of AND ACtion against Diabetes}

\author{
Laura Montesi* \\ doi: https://doi.org/10.31644/ED.V9.N1.2022.A09
}

\begin{abstract}
Resumen: En México, la diabetes mellitus, junto con otros desórdenes metabólicos, sigue incrementándose a pesar del despliegue de diversas estrategias de salud pública. Este artículo cuestiona las bases epistemológicas de estas estrategias y plantea la necesidad de un cambio de paradigma, alcanzable a través del intercambio entre conocimientos científicos y legos. Con base en ocho años de investigación etnográfica en un pueblo indígena de México, se describe cómo interpretaciones 'otras' de la diabetes —usualmente subalternizadas o ignoradas — presentan valiosos aportes epistémicos que resuenan con recientes avances científicos de tipo biosocial, que critican la autonomía del individuo y la separación cuerpo-mente y cuerpo-ambiente. Este diálogo, aunque permeado por tensiones, puede tener consecuencias trascendentales para el conocimiento y la acción ante la diabetes mellitus.
\end{abstract}

Palabras clave: Conocimientos populares sobre la diabetes, la antropología como trickster entre conocimientos sobre la diabetes, cambios epistémicos para conocer y atender la diabetes.

Abstract: Diabetes mellitus, as well as other metabolic disorders, are on the rise in Mexico, despite the implementation of several public health strategies. This article questions the epistemologic bases of such strategies and calls for a paradigm shift, achievable though the exchange between scientific and lay knowledges. Drawing on eight years of ethnographic fieldwork among an indigenous group in Mexico, it describes how 'other' interpretations of diabetes - usually subaltern or ignored- present valuable epistemic contributions that resonate with recent

\footnotetext{
* Dra. en Antropología, profesora investigadora Cátedra CONACyT con adscripción al Centro de Investigaciones y Estudios Superiores en Antropología Social, Unidad Pacífico Sur, México. ORCiD: https://orcid.org/0000-00018916-6776. Correo-e: lmontesi@conacyt.mx.
}

Fecha de recepción: 05/05/2021. Fecha de aceptación: 12/11/2021. Fecha de publicación: 31/01/2022.

\section{(cc) BY-NC-ND}

EntreDiversidades. Revista de Ciencias Sociales y Humanidades, Vol. 9, Núm. 1 (18), enero-junio 2022. Páginas: 223-246 ISSN-e: 2007-7610. https://doi.org/10.31644/ED.V9.N1.2022.A09 
biosocial scientific developments which criticize the autonomy of the individual and the body-mind and body-environment divide. This dialogue, although permeated with tensions, can have transcendental implications for how we get to know and act against diabetes mellitus.

Keywords: Peoples knowledge on diabetes, Anthropology as a trickster between understandings of diabetes, epistemic changes to know and address diabetes.

\section{Introducción}

Durante el último medio siglo, en México la prevalencia de diabetes mellitus ha estado en incremento, hasta el punto de que en el año 2000 esta enfermedad llegó a posicionarse como la primera causa de muerte en las mujeres y la segunda en los hombres (Shamah-Levy, T., et al., 2020: 45), manteniéndose entre las primeras dos causas de muerte hasta la pandemia de covid19. Como es ampliamente reconocido, la diabetes constituye el "motivo más frecuente de incapacidad prematura, ceguera y amputaciones de extremidades no causadas por traumatismos" y "[e]s una de las cinco enfermedades con mayor impacto económico al sistema de salud" (2020: 45). Aunque México presenta tasas de diabetes alarmantes, no es el único país en esta situación, habiéndose afirmado esta epidemia a nivel global.

Al agrandarse este problema de salud en magnitud y gravedad, los estudios en biología, genética, epidemiología y otras ciencias afines fueron multiplicándose, arrojando nuevos entendimientos de una enfermedad difícilmente descifrable, al ser sistémica, heterogénea, crónico degenerativa y multifactorial. Así, los estudios más recientes siguen diversas pistas explicativas, algunas resumidas en un artículo de revisión publicado recientemente en la revista Nature (Roden y Shulman, 2019): entre los factores causantes se mencionan ciertamente los cambios en el estilo de vida, pero también el rol que juegan la contaminación ambiental, la condición socioeconómica y psicosocial, los patrones de conducta de los genitores y las condiciones ambientales intrauterinas durante la gestación, entre otros.

Estas pocas líneas ya de por sí dan cuenta de la complejidad de la diabetes mellitus, hecho que queda de manifiesto en la incapacidad que se ha demostrado hasta la fecha para contenerla y, mucho menos, revertirla. En otras palabras, la práctica médica y las políticas públicas se han quedado cortas.

En este artículo ${ }^{1}$ sostengo que esto se debe a que sus enfoques se han concentrado en el plano de los estilos de vida, entendiéndolos como patrones conductuales individuales. Pero la argumentación va más allá de esto; también arguyo que para repensar las intervenciones en materia de salud se hace imperativo salir de la cómoda pero limitada postura del cambio comportamental

\footnotetext{
${ }^{1}$ Quisiera agradecer a todas las personas e instituciones que a lo largo de muchos años me brindaron la oportunidad de explorar y seguir interrogándome en torno a los procesos salud/enfermedad/atención, en particular, a la University of Kent, a la Wenner-Gren Foundation (grant n. 8884) y al Consejo Nacional de Ciencia y Tecnología (Conacyt). Reconozco el apoyo de Conacyt a través del programa Cátedras (recientemente renombrado Investigadoras e investigadores por México) y de mi institución de adscripción, Centro de Investigaciones y Estudios Superiores en Antropología Social (CIESAS) Pacífico Sur. Por supuesto, el agradecimiento más grande va a las y los pobladores ikojts. Gracias también a las o los dictaminadores anónimos y editores que me permitieron mejorar el manuscrito.
}

EntreDiversidades. Revista de Ciencias Sociales y Humanidades, Vol. 9, Núm. 1 (18), enero-junio 2022. Páginas: $223-246$ ISSN-e: 2007-7610. https://doi.org/10.31644/ED.V9.N1.2022.A09 
y asumir una mirada sistémica que considere los desarrollos científicos arriba mencionados que indican la porosidad y mutua implicación de cuerpo(s) y ambiente(s), y, finalmente, prestar atención a otras epistemologías que reconocen esta implicación mutua y que están presentes en los que denominamos "conocimientos legos", los cuales se encuentran subalternizados o francamente ignorados.

Se trata, básicamente, de establecer un auténtico diálogo entre sistemas de conocimientos científicos y legos. El mismo se ha desarrollado sobre todo en el ámbito de los estudios socioambientales:

Ciencias naturales y ciencias sociales han convergido, en varias ocasiones de manera interdisciplinaria, en la consideración de que dichos saberes [conocimientos y prácticas de los pueblos] son fundamentales, y se han preocupado por establecer, en lo posible, un diálogo con aquellos otros producidos por la ciencia moderna, la de la academia (Guerrero, 2015: 8).

Proyectos similares se han emprendido también en el ámbito de la antropología médica, disciplina que explora los procesos salud/enfermedad/atención (en adelante s/e/a) desde las experiencias y prácticas de los grupos sociales, lo cual ha permitido "agregar nuevas perspectivas a las interpretaciones del bienestar y subjetividades alternativas desde las cuales teorizar" (Gamlin y Berrio, 2020: 42, traducción propia). ${ }^{2}$

Sin embargo, en la disciplina también se ha cristalizado una tendencia hacia el representacionismo, es decir, se documentan y tratan los significados que "otros" tienen de los estados de salud y malestar como epifenómenos culturales (representaciones) de una realidad subyacente: la de los procesos fisiológicos humanos (Good, 1994: 6) definidos por la medicina occidental (para una crítica reciente véase Kolb, 2015). Este tipo de acercamiento inhibe la generación de un verdadero diálogo, tan necesario, entre epistemologías que pueda llegar a criticar, cuestionar, complejizar, ampliar o repensar los modelos explicativos dominantes.

Para dilucidar por qué es importante romper barreras entre sistemas de conocimientos, haré referencia a mi propia experiencia como antropóloga médica que ha trabajado con personas afectadas por la diabetes en zonas indígenas. En este sentido, considero que la antropología puede fungir como bróker o trickster entre ciencia occidental y conocimiento lego.

A lo largo de este artículo recurriré al término "conocimiento lego" porque me refiero a entendimientos de personas comunes, sin un grado de especialización como lo pueden tener los médicos tradicionales u otras figuras reconocidas como detentoras de un conocimiento especial por parte de su grupo social. Esto no implica que el conocimiento lego no sea sofisticado, coherente o estructurado; al contrario, constituye una episteme. En el caso que nos atañe, se trata de conocimiento lego en contexto indígena. Si bien me encuentro lejos de poder ofrecer una fórmula acabada y exitosa de intercambio entre conocimientos científicos y legos, aprovecho el espacio de este artículo para poner la cuestión sobre la mesa, esperando contribuir a los

${ }^{2}$ Trad. propia: "[...] the presence throughout Latin America of diverse indigenous medical systems has informed anthropological theory, adding new perspectives to interpretations of wellbeing, and alternative subjectivities from which to theorise" (Gamlin y Berrio, 2020: 42).

EntreDiversidades. Revista de Ciencias Sociales y Humanidades, Vol. 9, Núm. 1 (18), enero-junio 2022. Páginas: $223-246$ ISSN-e: 2007-7610. https://doi.org/10.31644/ED.V9.N1.2022.A09 
debates en torno a las posibilidades y los retos de un diálogo de este tipo, consciente de que este planteamiento está repleto de tensiones y controversias, que prefiero nombrar como "fricciones".

El artículo se desarrolla en cuatro partes: primero, se describe y critica la manera en que en México se ha desarrollado la política pública de salud para combatir la diabetes; en segundo lugar, se presentan dos ejemplos etnográficos de cómo una cultura indígena de México, los huaves o ikojts de Oaxaca, interpreta la diabetes; en la tercera parte, se contrasta este conocimiento lego con algunos desarrollos científicos recientes, mostrando áreas de potencial diálogo entre diversos sistemas de conocimiento. Por último, se discuten los riesgos y las fricciones que se generan al intercambiar saberes en situaciones de asimetría y se propone una reflexión sobre el rol que la antropología puede jugar en este proyecto de contaminación científica.

\section{El paradigma dominante: estrategias nacionales para la prevención y el control de la diabetes}

Si analizamos las acciones de salud pública más relevantes emprendidas en México hasta la fecha para hacer frente a la diabetes nos daremos cuenta de que su objetivo fundamental ha sido combatir el sedentarismo y los malos hábitos alimenticios, vistos como las principales causantes de la epidemia. La mayor parte de las intervenciones en el ámbito clínico se han concentrado en promover estilos de vida "saludables", exhortando a las personas a que se alimenten de una forma balanceada y hagan ejercicio.

Hasta hoy, la acción más ambiciosa remonta al lanzamiento en el 2013 de la "Estrategia Nacional para la Prevención y el Control del Sobrepeso, la Obesidad y la Diabetes” para hacer frente a lo que el gobierno mexicano definió como una "emergencia sanitaria" (Secretaría de Salud, 2013: 7). ${ }^{3}$ En la Estrategia se reconoce que la situación de morbimortalidad en México "es fruto de factores económicos, sociales, políticos y culturales" y que, por lo tanto, es necesario crear las condiciones para generar determinantes sociales positivas para la salud (2013: 11-12). Para esto, la Estrategia identificó tres pilares fundamentales: (i) salud pública, (ii) atención médica y (iii) regulación sanitaria y política fiscal.

Leyendo a detalle los ejes que componen los primeros dos pilares, destaca el énfasis puesto en la concientización de la población a través de campañas sobre nutrición y actividad física, la educación en salud y el autocuidado, además de la detección temprana del sobrepeso, la prediabetes y la diabetes. El tercer pilar se concentra en promover un etiquetado claro para el consumidor, regular la publicidad de alimentos y bebidas altamente calóricas, especialmente entre la población infantil, y generar una política fiscal con impuestos en alimentos y bebidas no nutritivas. ${ }^{4}$ Aunque estas acciones sean sumamente importantes, manifiestan una visión

\footnotetext{
${ }^{3}$ Con el cambio de administración en 2018, encabezado por el presidente Andrés Manuel López Obrador, ha habido un quiebre importante en la política pública respecto a temas como salud y alimentación. Sin embargo, estando estas acciones aún en desarrollo, consideramos prematuro evaluarlas; por lo tanto, tomamos como último y más reciente ejemplo de política pública en salud, particularmente enfocada en la prevención y atención de la diabetes, a la Estrategia Nacional del gobierno del expresidente Enrique Peńa Nieto.

${ }^{4}$ Este último punto solo se logró en 2019 con el cambio de régimen político, que llevó a la aprobación de las modificaciones a la norma oficial mexicana número 51 (NOM-051) sobre etiquetado en alimentos y bebidas.
}

EntreDiversidades. Revista de Ciencias Sociales y Humanidades, Vol. 9, Núm. 1 (18), enero-junio 2022. Páginas: 223-246 ISSN-e: 2007-7610. https://doi.org/10.31644/ED.V9.N1.2022.A09 
hipermedicalizada del problema, una adscripción al modelo comportamental de la enfermedad y un énfasis en el plan individual, conceptualizando lo colectivo como suma de consumidores.

Dentro de este paradigma, individuos y comunidades quedan descontextualizados, y la etiopatología de la diabetes pensada como consecuencia de estilos de vida insanos, diferencias biológicas y falta de adherencia terapéutica, dimensiones que se consideran modificables principalmente a través de la educación, la creación de espacios no bien definidos que faciliten la toma de buenas decisiones y terapias médicas personalizadas. Básicamente, nos encontramos ante una concepción del individuo como un ser autónomo y capaz de autorregularse puestas ciertas condiciones.

Es importante señalar que las desigualdades sociales y económicas mencionadas en la parte introductoria de la Estrategia desaparecen casi por completo en el desarrollo del texto. El término "desigualdad" comparece solo tres veces y no de manera sustantiva; tres veces se menciona "pobreza”, mientras que la única referencia a la "violencia" es en relación con la violencia familiar que, si bien es un fenómeno de importancia trascendente, no puede aislarse de las violencias estructurales; la "justicia” se nombra en una sola ocasión. Aún más llamativo es el hecho de que en ninguno de los ejes que componen los tres pilares de la Estrategia Nacional se detectan acciones específicamente pensadas con el fin de erradicar las desigualdades, atender las injusticias sociales, medioambientales y políticas, y atacar las múltiples violencias que sufren los y las mexicanas según líneas de discriminación étnica, lingüística, social y de género. Por supuesto, ampliar el acceso a la atención médica y elevar la calidad de los servicios son acciones dirigidas a fundamentar el derecho universal a la salud, pero aún en este segundo apartado gran parte de los propósitos se dirigen al "empoderamiento del paciente", tema deseable pero controversial cuando dicho empoderamiento se piensa desde un marco individual, sobre todo en un contexto como el mexicano en donde una porción importante de la población sufre por condiciones de vida (no estilos de vida) tan apremiantes que ponen a la sobrevivencia en primer plano y a la salud en segundo o tercero.

Este acercamiento a la salud se refleja en las principales iniciativas de prevención y control que se han implementado en el país. Ejemplo de esto es la campaña "Chécate, Mídete, Muévete" del Instituto Mexicano del Seguro Social (IMSS), que se difundió masivamente en los medios de comunicación, o la estrategia de los grupos de ayuda mutua para brindar atención a los pacientes crónicos y que se implementa de manera desigual y fragmentada en los centros de salud del país. Varios análisis han seńalado que estas iniciativas tienen un enfoque biologicista/ reduccionista (Sánchez-Reina y Brito, 2016) y actúan solamente en un plano microsocial, con limitados cambios estructurales (Menéndez, 2014).

Campañas de este tipo, que, por cierto, no son excepcionales en el concierto mundial, se enfocan demasiado en la autorregulación para alcanzar parámetros biométricos de normalidad y a menudo señalan y estigmatizan cuerpos no hegemónicos, produciendo efectos nocivos en la salud física y mental de las personas (Yates-Doerr, 2015). Además, su implementación queda rebasada por la realidad. Por ejemplo, Saldaña-Tejeda ha documentado cómo en el caso de niños con obesidad bajo tratamiento biomédico son las madres quienes son responsabilizadas por sus dietas,

EntreDiversidades. Revista de Ciencias Sociales y Humanidades, Vol. 9, Núm. 1 (18), enero-junio 2022. Páginas: 223-246 ISSN-e: 2007-7610. https://doi.org/10.31644/ED.V9.N1.2022.A09 
mientras que los padres quedan relegados de tal obligación, imponiéndoles, además, dietas difícilmente alcanzables, sobre todo para las que se dedican al trabajo doméstico, a menudo en condiciones laborales de explotación (Saldaña-Tejeda, 2014; 2018: 41).

La evidencia etnográfica, entonces, puesta en diálogo con la producción científica, nos permite dar un rostro y un contexto a las experiencias vividas de la diabetes. La mirada antropológica dentro de las experiencias cotidianas de personas y comunidades profundamente afectadas por la epidemia de diabetes arroja luz sobre las complejas sinergias socioambientales que contribuyen a la hiperglucemia crónica. Además, evidencia los efectos que tienen las desigualdades sociales en los grupos subalternizados. Finalmente, la escucha puesta en los modelos explicativos legos revela otras formas de entender el cuerpo y los procesos s/e/a, las cuales no pueden quedar como curiosidades antropológicas sino como fuentes de conocimiento capaces de poner de manifiesto los límites de paradigmas establecidos. En lo que sigue, me propongo demostrar la necesidad de emprender este camino, aunque sea incierto y resbaloso.

\section{Epistemologías “otras” de la diabetes}

En esta sección, como se anticipó, se presentan las experiencias vividas y narradas por hombres y mujeres de San Dionisio del Mar, comunidad ikojts con poco más de 3000 habitantes situada en el sur del Istmo de Tehuantepec en el estado de Oaxaca y en donde la diabetes constituye la primera causa de muerte según datos del 2015 verificables en la base de datos de la Dirección General de Información en Salud. Las elaboraciones narrativas de las experiencias con la diabetes revelan epistemologías del cuerpo subyacentes.

La información que reporto fue recabada entre 2013 y la actualidad, durante estancias de campo de diferente duración. Entre 2013 y 2014 realicé entrevistas semiestructuradas a 34 personas con diabetes, además de haber tenido múltiples conversaciones informales con personas con y sin la enfermedad. A lo largo del tiempo, pude ahondar en diversos temas relacionados con las concepciones locales del cuerpo y de los procesos s/e/a. En 2017 entrevisté a 13 jóvenes que conviven con familiares con diabetes para conocer su percepción de la enfermedad y su experiencia del cuidado (Montesi, en prensa). Lo que sigue deriva de este trabajo plurianual.

\section{De cuerpos emocionales y emociones corporeizadas}

Al tiempo de la entrevista, Magdalena ${ }^{5}$ era ama de casa y tenía 55 años, de los cuales 18 viviendo con la diabetes. Se acordaba bien cuándo y cómo empezó a sufrir los síntomas de la enfermedad:

Tuve un susto y empecé a tomar agua. [Tenía sed] y puro tomo agua. [Me dio] dolor de cabeza y sueño. El susto fue cuando metieron a la cárcel mis familiares, vino mi sobrina a decirme que su mamá ya la llevaron, dice. Me asusté porque la muchacha llegó llorando y luego tomé cerveza. A una semana de los eventos seguía yo tomando agua, agua y a cada ratito voy al baño. Entonces ya fui con el doctor. Me sacaron sangre y salió que yo ya tengo azúcar. Es por el susto y por lo

\footnotetext{
${ }^{5}$ Todos los nombres son ficticios.
}

EntreDiversidades. Revista de Ciencias Sociales y Humanidades, Vol. 9, Núm. 1 (18), enero-junio 2022. Páginas: $223-246$ ISSN-e: 2007-7610. https://doi.org/10.31644/ED.V9.N1.2022.A09 
que piensa uno. Ahora tomo las pastillas y con las pastillas estás tranquila. Pero de repente da dolor de cabeza y de cuerpo y no quieres que la gente te diga nada (Entrevista a Magdalena, San Dionisio del Mar, 11 de septiembre de 2013).

Magdalena, así como muchas de las personas con diabetes que entrevisté, anclaba el origen de este desorden en un evento traumático que la había marcado de por vida. La noticia de que unos familiares estaban siendo aprehendidos irrumpió en su vida de una manera dramática y repentina, generándole un susto que trastocó su equilibrio fincado en el balance frío/caliente, con efectos permanentes.

Como en muchas culturas mesoamericanas, también entre los huaves sigue vigente la idea de que una persona es saludable cuando lo frío y lo caliente - dos cualidades que no necesariamente reflejan la temperatura corpórea - se encuentran en balance, sin que uno prevalezca sobre el otro. Lo frío y lo caliente se adjudican también a la comida según específicos sistemas clasificatorios, por lo cual las decisiones cotidianas sobre la dieta incluyen la evaluación de estas características en los alimentos (Montesi, 2017a).

El extracto arriba reportado alude a que el tomar agua y cerveza (asociados con lo frío) después de haber experimentado un susto (asociado con lo caliente) rompe el equilibrio frío/ caliente que sostiene la salud. Este desequilibrio llega a afectar la sangre, develando una compleja relación entre emociones, frío/caliente y sangre. El relato, además, no solamente identifica un evento "agudo" detonador del susto, sino que también reporta que dicho suceso tuvo la capacidad de dejar a la persona en un estado de vulnerabilidad o susceptibilidad emocional. Como explica Magdalena al final de su relato: "no quieres que la gente te diga nada". Como ella, la mayor parte de las personas con diabetes entrevistadas evocaron muchas emociones detonadoras: susto, impresión, coraje, muina, enojo, desesperación, sentimiento, mucho pensar, tristeza, envidia, maldad, achaque, alegría repentina.

La relación entre estrés emocional y diabetes no existe solo en México, tanto entre la población indígena como en la mestiza, sino que ha sido documentada en varios contextos sociales entre sí muy diversos (Cabassa, et al., 2008; Wagner, et al., 2011), por lo tanto, se trata de una explicación etiológica y patofisiológica transcultural. Sin embargo, es importante no perder de vista las maneras específicas en que cada cultura concibe y experimenta lo emocional. En el caso huave, desde los estudios pioneros de Signorini y Tranfo (1979), se reconoce que existe un conjunto amplio y complejo de enfermedades atribuidas al estrés emotivo y ocasionadas por una acción humana; los autores se refieren a ellas como narangï̌ y reportan:

El narangïc a menudo se enlaza en el plano sintomático con condiciones emotivas críticas tales como la ira, la envidia llevada a niveles de constante tensión, la depresión y la excitación, ambas en su manifestación límite, el miedo. Pero todo esto, que para nuestra cultura médica es pura sintomatología, es considerado en el mundo huave, y en el mesoamericano en general, como una verdadera enfermedad, mientras que la causa, entendida solamente como humana y comportamental, es removida a una fase subyacente al hecho biológico (1979: 234).

EntreDiversidades. Revista de Ciencias Sociales y Humanidades, Vol. 9, Núm. 1 (18), enero-junio 2022. Páginas: 223-246 ISSN-e: 2007-7610. https://doi.org/10.31644/ED.V9.N1.2022.A09 
Signorini y Tranfo destacan una sustantiva discrepancia entre cultura médica occidental y cultura médica huave, la cual deriva de una concepción del cuerpo que se fundamenta en una comprensión biopsicoanímica unitaria en la que se entrecruzan la pérdida del equilibrio frío/caliente, la pérdida del alma y, hoy en día (a raíz de la epidemia de diabetes), los cambios en la calidad de la sangre que se vuelve "dulce".

Como reporté en otros trabajos (Montesi, 2018), en el plano anímico y emocional un rol fundamental lo juega el umyajts, término polisémico, difícilmente traducible, que indica la parte central del cuerpo y se emplea para referirse a la barriga y el corazón. Este constituye una de las sedes vitales por excelencia, además de ser capaz de sentir, pensar, recordar y regular la calidad y el ritmo de la sangre (2018: 215). Desde esta perspectiva, tiene sentido considerar que la diabetes se genera o acompańa por emociones fuertes que afectan el centro vital de la persona y todo el equilibrio biopsicoanímico. Estar asustados, pensar mucho o sentir desesperación no son dimensiones incidentales de la diabetes sino sustantivas: "Con el susto, la sangre se pone dulce" (Entrevista a Eusebio, San Dionisio del Mar, 2014).

En otro nivel de análisis, aquel que mira a las circunstancias sociales que propician la experiencia de emociones en sus manifestaciones límite, se evidencia que fenómenos como la inseguridad, el conflicto o la violencia cotidiana son marcadores fundamentales de la experiencia del padecer; estos fenómenos se multiplican en contextos sociales desiguales como el mexicano. La violencia, que como recuerdan Scheper-Hughes y Bourgois "es un concepto escurridizo, inefable —nonlinear, productivo, destructivo y reproductivo-” (2004: 1, traducción propia), ${ }^{6}$ parece incidir de manera contundente en las trayectorias vitales de las y los ikojts con diabetes.

Tal es el caso de Susana, 53 ańos y casi 20 con diabetes, quien relaciona su enfermedad con el asesinato de su padre, evento que ocurrió cuando ella todavía era niña. O el caso de Rutilio, 53 años y alrededor de 15 con diabetes, quien considera que sus síntomas se presentaron a raíz de vivir violencia policial, durante una manifestación política reprimida con la fuerza. La violencia también marcó la vida de Sergio, quien tuvo un cargo político que le trajo momentos de fuertes tensiones. A raíz de un susto sufrido durante un pleito, Sergio empezó a enfrentar los retos de la diabetes: "Ya me dijo el doctor 'tienes azúcar, procura curarte ahora" (Entrevista a Sergio, San Dionisio del Mar, 20 de septiembre de 2013).

Estos testimonios resuenan con las narrativas recolectadas por Loza Taylor (2017) en una comunidad mestiza/indígena del estado de Morelos o con la trayectoria de una mujer guatemalteca establecida en Chiapas documentada por Jaime Page (2019). Para Loza Taylor, "violencia, emoción y enfermedad encuentran un punto de referencia en el cuerpo de las personas afectadas" por la diabetes (2017: 593). Asimismo, Page reconoce este vínculo y, al seguir las vicisitudes de esta mujer guatemalteca — víctima de la pobreza, la violencia armada y la discriminación racial vinculada con su estatus migratorio ilegal—- contextualiza su diabetes dentro de un cuadro de violencia estructural y política.

Lo presentado hasta aquí indica que los cuerpos son ante todo emocionales y que las emociones están en todo momento corporeizadas, actantes en cuerpos cultural y socialmente

${ }^{6}$ Trad. propia: "Violence is a slippery concept—nonlinear, productive, destructive, and reproductive [...]" (Scheper-Hughes y Bourgois, 2004: 1).

EntreDiversidades. Revista de Ciencias Sociales y Humanidades, Vol. 9, Núm. 1 (18), enero-junio 2022. Páginas: $223-246$ ISSN-e: 2007-7610. https://doi.org/10.31644/ED.V9.N1.2022.A09 
situados (Csordas, 1994). Las distinciones entre cuerpo y alma, cuerpo y psique, son un constructo cultural occidental ya fuertemente problematizado, incluso dentro de los campos de estudio científicos, los cuales han avanzado mucho en el entendimiento de las relaciones entre cuerpo, mente y entorno físico y sociocultural.

\section{"Química”, contaminaciones ambientales y debilidad}

En San Dionisio del Mar, que las emociones fuertes y el sufrir ocasionen y acompañen la diabetes llega a un tal punto de consenso que pueden considerarse una verdad. Sin embargo, esta explicación etiológica no es siempre suficiente. Claudia, quien al tiempo de la entrevista llevaba tres años con un diagnóstico de diabetes, se preguntaba lo siguiente: "No tengo idea de por qué me dio diabetes. Porque aquí [en mi casa] nunca peleamos, nunca estamos discutiendo. Vivo tranquila con mi marido. [...] Hay gente que tiene problemas, deudas, montón de hijos, que se preguntan cómo van a vivir, ¿pero nosotros qué?” (Entrevista a Claudia, San Dionisio del Mar, 7 de septiembre de 2013). Frente a esta pregunta sin respuesta que soslaya incertidumbre existen otros planos explicativos elaborados por los pobladores huave. En el trabajo de campo, otra constante ha sido la vinculación entre el consumo de alimentos con "químico" y el deterioro de la salud, hecho documentado también por Kolb entre los totonacos de Puebla: "los químicos en la comida han resultado en la introducción de la diabetes al pueblo, pero no en los casos individuales" (2015: 165). Es decir, si en el nivel personal casi siempre la etiología evocada se enraíza en circunstancias que provocan emociones fuertes, en el plano colectivo el cambio alimentario cobra relevancia.

En las personas de cincuenta y más ańos que se consideran testigos de un mundo antiguo desvanecido bajo las influencias de un rápido cambio social (una suerte de "gran aceleración" en el nivel local) existe la percepción de que las condiciones de salud de la población se han deteriorado y que sus cuerpos se han vuelto más frágiles. Esta percepción parece contrastar con datos importantes de morbimortalidad que apuntan a un aumento de la esperanza de vida, a un mejor control de las enfermedades infecciosas y a un descenso de la mortalidad materna, entre otros.

Este tipo de "paradoja" ha sido documentado en otros contextos indígenas, por ejemplo, entre los matsigenka de la Amazonia peruana, quienes también perciben un deterioro en su salud a pesar de que los indicadores biomédicos indiquen sustanciales mejorías. Según Izquierdo (2005), esto se debe a discrepancias conceptuales en la definición de "salud", ya que para los matsigenka la ausencia de enfermedad es solo un componente del bienestar, el cual para ellos incluye otros estados ideales como la felicidad, la productividad y la bondad.

Así, entre los huaves, son recurrentes los comentarios acerca de cómo, generación tras generación, la capacidad de trabajo y la resistencia ante las enfermedades ha ido disminuyendo. Innumerables veces he escuchado a adultos con diabetes comentar que sus padres o suegros están sanos y que los abuelos murieron "centenarios", también que los jóvenes ya "no aguantan" la carga de trabajo. Esta apreciación queda bien encapsulada por una metáfora agrícola muy sugestiva evocada por Pedro, un campesino huave cuya esposa tiene diabetes: "En la primera

EntreDiversidades. Revista de Ciencias Sociales y Humanidades, Vol. 9, Núm. 1 (18), enero-junio 2022. Páginas: 223-246 ISSN-e: 2007-7610. https://doi.org/10.31644/ED.V9.N1.2022.A09 
cosecha, las sandías salen grandes; en la siguiente, salen más pequeñas y luego más pequeñas aún. Así parecen los jóvenes, cada generación salen más débiles” (Montesi, 2017a: 105-106).

Este tipo de percepciones en torno a un deterioro en la fuerza y la energía de las generaciones más jóvenes amerita un escrutinio profundo, ya que nos interroga sobre el significado subjetivo y cultural de la salud y el bienestar, además de que indica que hay una sensación compartida de fragilidad e inseguridad frente al futuro. Por supuesto, las percepciones que los adultos tienen de las personas más jóvenes, vistas como menos dadas a la fatiga, se relacionan con procesos más amplios como lo es la disminución de las actividades primarias, fenómeno debido a la desagrarización del campo y al consecuente aumento de una población rural siempre más dependiente de y subordinada al mercado laboral urbano (Carton de Grammont, 2009). Estos procesos macroestructurales conllevan rupturas que se pueden manifestar en el orgullo por las actividades campesinas, vistas como baluarte de un modo de vida "sano" aunque arduo. La alimentación queda justo en el cruce de estos procesos, viéndose afectada de manera directa por los cambios en los modos de subsistencia y reproducción. Hablando de la epidemia de diabetes, Pedro me compartió este análisis:

Antes no hay ese problema de la enfermedad. Sí, se escucha en la ciudad, pero no en el pueblo. [...] Nosotros lo que estamos pensando, analizando las cosas, es que anteriormente, cuando yo era chico, tomábamos atolito de maíz cocido en la olla y comíamos pescado del mar, no viene del hielo [congelado], del mar al plato directamente. [...] Tomábamos agua del pozo, ahora lo preparan con la química y hay uno que toma mucha cerveza, se engorda, ahí infecta la enfermedad. Por ejemplo, ese pollo ahorita llega de afuera, es de granja y come alimento, no come maíz, se ve muy gordo, pero no es sabroso. [...] Ahora el mar se fue pa' bajo, ya no hay tanto producto como antes, no sé por qué. [...] ¿Y el campo? Mira, ahora de tanto que llovió fracasó el campo. Al principio [cuando era temporada de lluvia] no llovió, secó el campo, murió la milpa de sequía. Tanto el campo como el mar están bajando. Antes el mar era rico, pero ahora ya está escaso o ya tienen maña los animales (Entrevista a Pedro, San Dionisio del Mar, 11 de octubre de 2013).

Como ya he expuesto en otro trabajo (Montesi, 2017), los pobladores huaves relacionan su estado de salud con malos hábitos alimenticios, pero también con un cambio más profundo en la calidad de los alimentos que llegan a sus mesas. Pedro, con gran capacidad de observación y lucidez analítica, denuncia por lo menos tres grandes temas: la imprevisibilidad de los ciclos meteorológicos y agrícolas; la industrialización de la producción alimentaria que incide en el consumo; la disminución y alteración de la calidad de los alimentos de origen animal, incluso el producto pesquero del cual los huaves dependen.

Asimismo, Raquel, una mujer de 55 años y con 18 años desde su primer diagnóstico de diabetes, despierta interrogantes y observaciones similares a las de Pedro:

¿Será por herencia? No. Mi mamá nunca platicó de esta enfermedad. Ahí está pobre mi papá, no tiene [diabetes], todavía está vivo. ¿Y por qué yo? Ahorita bastante gente tiene esa enfermedad. Dice el doctor que antes nosotros nunca comíamos cosas de hielo, comemos de rancho, el pollo

EntreDiversidades. Revista de Ciencias Sociales y Humanidades, Vol. 9, Núm. 1 (18), enero-junio 2022. Páginas: 223-246 ISSN-e: 2007-7610. https://doi.org/10.31644/ED.V9.N1.2022.A09 
no hay ese de engorda, y no hay agua purificada, puro de pozo. Ahora tomo agua de garrafón, pero antes lo iba a traer del pozo mi papá, luego mi mamá lo echa en una manta, lo amarra en su olla, [lo filtra] y eso vamos a tomar. No es la raza de la gente, porque mi abuelita murió y nunca tuvo esa enfermedad. Murió mi otro abuelito y ni un día platicó que tiene azúcar. Ahorita toda la gente tiene ese. Ahorita, ya joven, ya tiene ese. ¿Por qué pues? (Entrevista a Raquel, San Dionisio del Mar, 11 de septiembre de 2013).

Aquí Raquel descarta que la diabetes tenga que ver con una predisposición genética de tipo racial, pues tiene el recuerdo de abuelos sanos. Por otra parte, la enfermedad ahora no solo es común, sino que afecta a personas siempre más jóvenes. Raquel menciona el cambio alimentario, evocando tres ejemplos: la comida congelada en lugar de fresca, el pollo de engorda en lugar del de rancho, el agua tratada y embotellada en lugar de la de pozo. Se detectan entonces varias alteraciones potencialmente problemáticas en la cadena de suministro de alimentos: la conservación prolongada, la alteración de los ritmos de crecimiento de los animales y el tratamiento con "químicos".

Las palabras de Pedro y Raquel — comunes, no extraordinarias - complejizan la relación alimentación-diabetes y apuntan a que esta enfermedad no se debe solamente a malos hábitos alimenticios individuales, sino a una alteración mucho más amplia y profunda de los sistemas alimentarios. De hecho, la investigación científica en torno a la industrialización global de los sistemas alimentarios muestra varias aristas en cuanto a su incidencia en los metabolismos, ya sea de organismos o de ecosistemas. Una vez más, nos encontramos ante interesantes cruces entre conocimientos legos y científicos.

\section{Diálogos entre miradas huaves y perspectivas científicas}

En el desarrollo del pensamiento occidental se han sucedido y contrastado diversas ideas acerca del ser, por lo tanto, sería una falacia asumir homogeneidad y permanencia. Sin embargo, tampoco se puede obviar que algunas concepciones han llegado a tener un peso específico, tanto a nivel de imaginarios compartidos como de principios organizadores de las relaciones sociales. Es este el caso del dualismo cuerpo/mente y de la noción del cuerpo como máquina, ideas que han influido enormemente en la ciencia y la biomedicina y, a la vez, en parte del sentir popular.

El dualismo cuerpo/mente quedó conceptualizado de manera explícita en la obra del filósofo francés René Descartes (1596-1650), quien en sus Méditations métaphysiques se dedicó a probar "que no sólo son diversas la naturaleza del espíritu y del cuerpo, sino que en cierto modo son opuestas" (Descartes, 2006: 59). Así, estableció un racionalismo radical con el que quedaba plasmado un hiato profundo entre cuerpo y espíritu (o mente).

Descartes postuló también la idea del cuerpo como máquina, consagrada en su obra L'Homme (conclusión del tratado Le Monde), y cuya concepción refleja plenamente los desarrollos de la revolución científica del siglo XVI (Maldonato y Anzoise, 2013: 439). La metáfora del cuerpo-máquina ha sido tan influyente que aún en la actualidad permea una

EntreDiversidades. Revista de Ciencias Sociales y Humanidades, Vol. 9, Núm. 1 (18), enero-junio 2022. Páginas: 223-246 ISSN-e: 2007-7610. https://doi.org/10.31644/ED.V9.N1.2022.A09 
parte importante de la enseñanza de la medicina, como bien lo documenta Ramírez Galván Rasgado (2020) en su etnografía sobre las prácticas de enseńanza-aprendizaje en la facultad de medicina de una universidad mexicana. En una entrevista, un profesor de la materia de anatomía explicó: "Creo que la Medicina se estudia como si estuviéramos viendo el motor de un carro" (Ramírez Galván, 2020: 147).

Sin embargo, a través del tiempo, otras representaciones del cuerpo han ido sucediéndose: en el siglo XX, por ejemplo, se desarrolló la metáfora computacional, relacionada con la revolución cibernética (Maldonato y Anzoise, 2013: 439), en la que el binomio cartesiano no desvaneció sino que se camufló en el binomio hardware/software o cerebro/mente (2013: 443), en el cual el cerebro es la res extensa que permite las operaciones de la res cogitans. Para Meloni (2019) otra influencia importante en la metáfora cibernética la han tenido los estudios de genética que promueven la idea de que los genes son "la fuerza controladora de los procesos vitales" (2019: iii, traducción propia), ${ }^{7}$ al "programar" la vida desde su inicio (Peluffo, 2015).

En cambio, arguye Meloni, con el advenimiento de disciplinas postgenómicas a partir del siglo XXI la centralidad de los genes como programadores de los desarrollos biológicos de un organismo ha encontrado creciente inconformidad conduciendo a un movimiento de "nociones de fijeza biológica a ideas de plasticidad e 'impresionabilidad' del material biológico" (2019: iii, traducción propia). ${ }^{8}$ Los estudios de epigenética son un claro ejemplo de esto, ya que las influencias ambientales tienen efectos trascendentes en las expresiones de los genes, por lo cual el desarrollo biológico no es enteramente comprensible y predecible a partir de un mapeo genético exhaustivo. Es decir, los cuerpos son porosos, dotados de plasticidad, a la vez que expuestos e impuestos a otros.

Estas conceptualizaciones cobran particular importancia en el mundo contemporáneo, el de la sociedad del riesgo (Beck, 1992), en donde las intervenciones humanas alteran al ambiente generando nuevos riesgos — piénsese en la industria nuclear, pero también en industrias más mundanas como la farmacéutica, con la inmisión siempre creciente de antibióticos en nuestras vidas y la consecuente resistencia que esto detona- o el del Antropoceno, en donde el ser humano se ha convertido en una fuerza geológica capaz de interferir en los procesos bio-químico-físicos de enteros ecosistemas.

Por otra parte, la plasticidad del cuerpo, o más bien de los cuerpos, se ha acompañado por una ruptura del binomio cuerpo/mente, especialmente en disciplinas como la psicología fisiológica y las neurociencias. Así, las emociones han pasado de ser consideradas afecciones contrapuestas al raciocinio y experiencias totalmente fuera de nuestro control a experiencias biopsicosociales que juegan un rol crucial en diversos procesos del inconsciente y de la cognición y que, además, están profundamente influidas por la sociedad y la cultura. Ya en la mitad de los años 90 del siglo pasado el neurocientífico António Damásio exponía "el error de Descartes"

\footnotetext{
${ }^{7}$ Trad. propia: "During the twentieth century, genes were considered the controlling force of life processes" (Meloni, 2019: iii).

${ }^{8}$ Trad. propia: "The rise of epigenetics in particular signals a shift from notions of biological fixedness to ideas of plasticity and "impressionability" of biological material" (Meloni, 2019: iii).
}

EntreDiversidades. Revista de Ciencias Sociales y Humanidades, Vol. 9, Núm. 1 (18), enero-junio 2022. Páginas: 223-246 ISSN-e: 2007-7610. https://doi.org/10.31644/ED.V9.N1.2022.A09 
y pregonaba que "sin cuerpo, no hay mente" y que el "self" o "yo" no era "una personita —el infame homunculus - dentro de nuestro cerebro" sino "un estado biológico que se reconstruye de continuo" (Damásio, 1994: 252).

En el mismo tenor, en los últimos años han crecido los estudios enfocados en entender cómo el ambiente influye en la salud física y emocional de las personas; por ejemplo, se ha puesto de relieve que la pérdida de contacto con la "naturaleza" en nuestras sociedades contemporáneas está repercutiendo en las emociones, la salud mental e incluso en las capacidades cognitivas (Bratman, Hamilton y Daily, 2012), o cómo las desigualdades sociales (inclusive las de ingresos) afectan la salud (Pickett y Wilkinson, 2015).

Ahora bien, más allá de las específicas posturas teóricas respecto a la naturaleza de las relaciones cuerpo/mente y cuerpo/ambiente, lo que aquí cabe resaltar es que queda siempre más claro que las interconexiones entre organismos, cuerpos y ambientes destacan por su profundidad, complejidad, multiplicidad e implicación mutua. Esto abre escenarios epistémicos distintos a los que se han basado en ideas como las de individuo (un ser indivisible y autónomo), cuerpo-máquina o cuerpo-computadora. Y estos desarrollos científicos y filosóficos cuestionan los acercamientos dominantes que hemos venido elaborando ante problemáticas de la salud como la diabetes mellitus durante las últimas décadas, basados en un tipo de educación que responsabiliza excesivamente al individuo con sus 'elecciones' o estilos de vida.

Sin embargo, como advierte Meloni, tampoco hay que pensar que plasticidad (plasticity) e imbricación (embeddedness) son nociones del todo nuevas; incluso en el pensamiento occidental anterior a la Ilustración han prevalecido teorías del cuerpo y del ser basadas en la plasticidad y la íntima interpenetración entre ser y ambiente. Por ejemplo, escribe Meloni, es este el caso de las teorías humorales que demuestran la "naturaleza impresionable de la biología antigua y de la temprana edad moderna" (2019: 35-36, traducción propia). ${ }^{9}$

Y si esto es así en las mismas sociedades occidentales, ¿qué decir entonces de las ideas de cuerpo y salud existentes en poblaciones no occidentales, que conservan otras miradas a pesar de la aculturación agresiva hacia ontologías "modernas"? Y si han estado a salvo de concepciones tan individualistas y mecanicistas del cuerpo, que, excepto por algunas ventajas específicas, han demostrado sus límites ante los actuales desafíos a la salud, ¿por qué no se les ha prestado atención? Es justo esto lo que intento traer a colación en este artículo. Regresemos, entonces, al caso de la diabetes.

La relación entre emociones fuertes (experimentadas en circunstancias sociales adversas) y diabetes es reconocida de manera contundente en el pensamiento lego. Al revés, en la práctica clínica, usualmente es minimizada, ya que el enfoque está puesto en la obtención del control glicémico a través de la dieta y de los tratamientos farmacológicos. La atención psicológica, cuando se brinda, se centra en el momento del diagnóstico y se ofrece para que el paciente acepte la enfermedad (o más bien la versión de la diabetes propuesta por la biomedicina) y supere la fase de negación para, de esta manera, apegarse al tratamiento. Aunque pueda haber un reconocimiento de que las emociones influyen en el control de la enfermedad, rara vez se explora

${ }^{9}$ Trad. propia: “[...] the impressionable nature of ancient and early modern biology” (Meloni, 2019: 35-36).

EntreDiversidades. Revista de Ciencias Sociales y Humanidades, Vol. 9, Núm. 1 (18), enero-junio 2022. Páginas: 223-246 ISSN-e: 2007-7610. https://doi.org/10.31644/ED.V9.N1.2022.A09 
su rol y alcance en la etio- y fisiopatología. Son contadas las ocasiones en las que se consideran las circunstancias de vida de los pacientes, sus aflicciones, dilemas morales, frustraciones.

La antropóloga Kaja Finkler (1994) ha denominado "lesiones de la vida" a "las adversidades percibidas de la existencia, incluyendo las relaciones sociales adversas, y las contradicciones irresueltas en las cuales una persona se encuentra atrapada y que erosionan su ser" (1994: 15, traducción propia). ${ }^{10}$ Estas lesiones, invisibles y no directamente relacionadas con lesiones orgánicas observables "son tan virulentas como cualquier otro patógeno hallado en la naturaleza" (1994: xii, traducción propia). ${ }^{11}$ Según esta autora, el deterioro crónico de la salud tiene mucho que ver con las lesiones de la vida. La diabetes, así como muchas narrativas del padecer parecen indicar, ¿podría ser la manifestación incorporada de estas lesiones invisibles y acumuladas en el tiempo? Si bien múltiples y complejos factores biológicos y sociales están en juego, una extensa literatura científica ha relacionado la exposición al estrés emocional con la diabetes (Kelly e Ismail, 2015). Muchos trabajos antropológicos han puesto en evidencia las sinergias entre diabetes, estados depresivos y situaciones de vida marcadas por distintos tipos de violencias, entre ellas la intrafamiliar en sus múltiples expresiones (Mendenhall y Jacobs, 2012). Asimismo, las historias de las personas que evoqué arriba apuntan a procesos biosociales en donde desigualdades sociales, violencias y enfermedades crónicas se entrelazan.

La famosa investigación "Whitehall" —así llamada porque se refiere al complejo administrativo de Londres donde se desempeñan los funcionarios británicos—, que empezó en 1967 desarrollándose por diez años durante su primera fase, arrojó luz sobre el impacto que las jerarquías sociales tienen en la salud. Básicamente, esta serie de estudios epidemiológicos demostraron que hay una relación inversa entre estatus (relacionado al grado laboral) y prevalencia de enfermedades crónicas (sobre todo cardiovasculares). Estas conclusiones indicaron que las jerarquías y las desigualdades se inscriben en los cuerpos y tienen un impacto que trasciende los estilos de vida individuales (Marmot, et al., 1978). A esto se le ha llamado el "gradiente social" de los procesos salud-enfermedad. Así, la desproporcionada carga de desórdenes metabólicos entre poblaciones colonizadas o subalternizadas muestra que las altas prevalencias "no son el resultado de una 'transición,' sino más bien de una sedimentación de desventajas" (Vaughan, 2019: 138, traducción propia). ${ }^{12}$ El paradigma antropológico del embodiment, o incorporación, tiene entonces su contraparte científica, al haberse demostrado que las circunstancias sociales se materializan en los cuerpos.

La diabetes como síntoma y expresión del sufrir (Leal y Lang, 2006; Montesi, 2017b) queda ampliamente ignorada por la "mirada médica" que privilegia el dato fisiológico y opera a través de una separación entre cuerpo y mente. Aunque los médicos sean empáticos con sus pacientes, su propia formación, las carencias infraestructurales y la ideología que subyace a las intervenciones

\footnotetext{
${ }^{10}$ Trad. propia: "By life's lesions, I mean the perceived adversities of existence, including inimical social relationships, and unresolved contradictions in which a human being is entrenched and which gnaw at the person's being" (Finkler, 1994: 15).

${ }^{11}$ Trad. propia: “[...] what I identify as life's lesions [...] are as virulent as any pathogen found in nature" (Finkler, 1994: xii).

${ }^{12}$ Trad. propia: “[...] are not the result of 'transition' but of a sedimentation of disadvantage” (Vaughan, 2019: 138).
}

EntreDiversidades. Revista de Ciencias Sociales y Humanidades, Vol. 9, Núm. 1 (18), enero-junio 2022. Páginas: 223-246 ISSN-e: 2007-7610. https://doi.org/10.31644/ED.V9.N1.2022.A09 
de salud pública no permiten atender este trastorno psicofísicoemocional en su totalidad. El resultado es que las heridas emocionales de los pacientes quedan desentendidas y desatendidas, sin hablar de las causas estructurales que las han generado.

En síntesis, tomar en consideración el conocimiento lego que establece de manera tan clara un vínculo entre emoción y diabetes nos lleva a: comprender que la experiencia de la diabetes se enmarca dentro de procesos biográficos que se desarrollan a través de un entramado de desventajas sociales y micro-macro violencias, que a veces se presentan como "agudas" (en un evento específico y traumático), otras veces, como "crónicas"; identificar una unidad psicofísicoemocional que desafía entendimientos biomédicos dominantes que se enfocan casi únicamente en los procesos fisiológicos; percatarnos de que la diabetes se ha convertido, entre otras cosas, en un idiom of distress, es decir, "formas socialmente y culturalmente apropiadas de vivir y expresar la aflicción en mundos locales" (Nichter, 2010: 405, traducción propia) ${ }^{13}$ lo cual interroga las capacidades y posibilidades que tiene la medicina de atender estas expresiones.

En cuanto al segundo eje de explicaciones legas, vimos que los huaves detectan como culpable a "la química", o ese conjunto de sustancias que desde la ciencia sabemos que interfieren con nuestros sistemas endócrinos y contribuyen al desarrollo de desórdenes metabólicos. En San Dionisio, la química es reconocida particularmente en algunos alimentos de la dieta cotidiana; entre estos, el pollo de granja, el maíz que se vende en las tiendas y el agua embotellada. El pollo de granja se contrapone con el pollo "de rancho", el que se cría en los patios de las casas; el maíz que se vende en las tiendas tiene un origen desconocido y ajeno, llegando de los estados del norte del país, y se considera producido de manera intensiva, contrariamente al maíz chico de producción campesina; el agua embotellada se asocia a tratamientos artificiales que la alteran en contraste con el agua "de pozo".

El caso del agua es bastante curioso, ya que ilustra las contradicciones que caracterizan a la sociedad del riesgo. El agua purificada ha sido promovida a partir de los años ochenta del siglo pasado por el centro de salud de la comunidad, el cual, desde entonces, recomienda hervir el agua o comprarla embotellada, claramente para evitar infecciones. Hoy día, el consumo de agua embotellada en San Dionisio es generalizado. Sin embargo, esto no evita que muchas personas manifiesten insatisfacción con el líquido: consideran que tiene menores propiedades nutritivas y organolépticas (sabe dulce y no satisface, "no te llena"), implica un costo mientras que el agua de pozo es compartida, idealmente disponible para todos, y sospechan que el cloro usado en el proceso de purificación a largo plazo es dañino. Además, se preguntan por qué desde que toman agua embotellada las personas "más se enferman", por ejemplo, de diabetes. Estos testimonios visualizan una paradoja de la sociedad contemporánea: se vive con mayores precauciones ejercidas cotidianamente en el plano individual y, al mismo tiempo, hay la sensación de estar más expuestos a enfermedades sobre las cuales se puede ejercer poco control. Algo parecido lamentan los matsigenka, que observan:

${ }^{13}$ Trad. propia: "Idioms of distress are socially and culturally resonant means of experiencing and expressing distress in local worlds" (Nichter, 2010: 405).

EntreDiversidades. Revista de Ciencias Sociales y Humanidades, Vol. 9, Núm. 1 (18), enero-junio 2022. Páginas: $223-246$ ISSN-e: 2007-7610. https://doi.org/10.31644/ED.V9.N1.2022.A09 
No teníamos que hervir el agua y vivíamos en paz. Éramos felices sin tener que lavarnos las manos todo el tiempo y ahora el personal de salud viene y dice que tenemos que lavarnos las manos a cada rato, hervir todo, y tener letrinas para ser felices, pero nosotros éramos felices antes (Amalia, mujer de 25 años) (Izquierdo, 2005: 767, traducción propia). ${ }^{14}$

La coexistencia de asepsia y presencia de contaminantes derivados de los mismos productos y procesos que se ocupan para garantizar esa asepsia también está siendo objeto de interés científico.

Por otra parte, es creciente la investigación acerca de los efectos ramificados que tiene la proliferación de químicos sintéticos orgánicos e inorgánicos en el ambiente (Guthman, 2011: 100). Según varios estudios, la exposición a pesticidas, tintes, plásticos, medicamentos, aditivos alimentarios, entre otros, han configurado una compleja "ecología tóxica” cuyos alcances aún no comprendemos del todo, pero que tienen verificados efectos disruptores en el sistema endócrino que regula las hormonas y el metabolismo (2011). Los estudios epigenéticos están explorando la posibilidad de que estos cambios se puedan transmitir a nivel intergeneracional, por lo cual la exposición a toxinas podría generar efectos diferidos en el tiempo, hecho que rinde más compleja la detección de cadenas causales (2011: 104).

Pero la exposición no es equitativa: estudios llevados a cabo en Estados Unidos, demuestran que latinos, afroamericanos e individuos de bajo ingreso están más expuestos a disruptores endócrinos diabetogénicos, por lo cual las diferencias etnorraciales en las prevalencias de diabetes pueden explicarse como el efecto de injusticias socioambientales (Ruiz, et al., 2018).

La segregación racial y la racialización del mercado laboral determinan que ciertos grupos sociales estén más involucrados en trabajos que requieren contacto con contaminantes (véase el caso de los trabajadores agrícolas mexicanos en Holmes, 2013), consuman comida enlatada, en embalajes de plástico y con aditivos alimentarios y residan en áreas contaminadas o con pocos espacios verdes.

Desde esta óptica, algunos científicos están cuestionando la clasificación de la diabetes como una enfermedad "no transmisible". Si bien la diabetes no es contagiosa, puede que existan agentes patógenos que fomenten su transmisión (Seeberg y Meinert, 2020), por ejemplo, los contaminantes ambientales. Desde esta perspectiva, la diabetes sería transmisible, aunque no infecciosa.

En el caso que nos atañe, el del istmo oaxaqueño, es complejo identificar las fuentes contaminantes. Hasta donde tengo entendido, no hay estudios epidemiológicos de amplia envergadura que retraten la relación entre contaminación y salud en la región. Sin embargo, las observaciones etnográficas sugieren algunas pistas que ameritarían ser estudiadas.

La dieta local ha sido invadida por productos industrializados de baja calidad nutricional y se han integrado sobre todo en las dietas de niños y niñas. La gente observa una disminución del producto pesquero, quizás por la sobreexplotación de las lagunas (Cuturi, 1990) y su

\footnotetext{
${ }^{14}$ Trad. propia: "We didn't have to boil water and we lived in peace. We were happy without having to wash our hands all the time and now health personnel come and say we have to wash our hands all the time, boil water for everything, and make latrines to be happy, but before we were happy (Amalia, a 25-year-old Matsigenka woman)" (Izquierdo, 2005: 767).
}

EntreDiversidades. Revista de Ciencias Sociales y Humanidades, Vol. 9, Núm. 1 (18), enero-junio 2022. Páginas: 223-246 ISSN-e: 2007-7610. https://doi.org/10.31644/ED.V9.N1.2022.A09 
contaminación. El ecosistema de las lagunas, de las cuales dependen los pueblos huave y zapoteca, necesita ser preservado para que sus habitantes humanos y no humanos puedan coexistir. El cambio climático está determinando grandes desafíos al cultivo de maíz (como también a los ciclos acuáticos de las lagunas), aumentando la dependencia de insumos externos. Finalmente, cabe añadir que en toda la región del istmo el sistema de recolección y gestión de la basura es ineficiente, lo cual ha determinado una situación en la que los pobladores tienen que vivir cerca de basureros a cielo abierto. Las familias no tienen más remedio que quemar los desechos, incluso productos altamente tóxicos como plásticos y baterías. Todo esto sin mencionar el gran desarrollo petrolero de la región, de cabo a cabo del istmo. El istmo veracruzano, con el puerto de Coatzacoalcos, ya es considerado un "infierno ambiental". ${ }^{15}$ A comienzos de los ańos 2000, Bozada y Bejarano (2006) publicaron resultados de un análisis de contaminantes orgánicos persistentes (COP) en el istmo y en el caso del complejo lagunar del Pacífico reportaron la presencia de sustancias con propiedades cancerígenas en el tejido adiposo de camarones, base de la alimentación huave.

Desde el nivel global, se están buscando nuevos mapas interpretativos para concoer los nexos entre salud, medioambiente y economía política. Ejemplo de esto es el lanzamiento por la revista biomédica The Lancet del concepto de "sindemia" (acuñado por los antropólogos Merrill Singer y Hans Baer desde los ańos 90) aplicado a la obesidad, vista como parte de una interrelación entre malnutrición y cambio climático (Swinburn, et al. 2019). Las implicaciones que este tipo de entendimiento tienen aún quedan por verse, pero promete ofrecer soluciones colectivas y sistémicas más que individuales. Por otra parte, y como bien lo señalan Emily Mendenhall y Merrill Singer (2019), también se corre el riesgo de que esta narrativa "global" oculte las formas en que la sindemia se manifiesta en cada contexto histórico y sociocultural. Para esto, la integración de metodologías etnográficas y biológicas será imprescindible (Roberts y Sanz, 2018). En la siguiente y última sección muestro ejemplos de los riesgos presentes en el diálogo entre conocimientos científicos y legos, y el rol que la antropología podría jugar en propiciar y cuidar este diálogo.

\section{Reflexiones finales: Antropología ¿̨bróker o trickster?}

En la sección anterior, se mostraron los potenciales puntos de contacto entre conocimientos legos y científicos, y se argumentó que si se diera un intercambio serio y horizontal se podrían generar mejores entendimientos de las problemáticas sociales que nos incumben. Sin embargo, es importante no romantizar este diálogo y reconocer que está permeado por tensiones. Existen diferencias epistemológicas subyacentes y asimetrías de poder que pueden determinar que la práctica científica coopte o "corrompa" los conceptos legos. Por esta razón, este diálogo entre conocimientos hay que entenderlo como una "fricción”, de manera similar a la definición de Anna

${ }^{15}$ Hay que señalar que actualmente se están promoviendo esfuerzos por abordar de manera holística salud-alimentación-medioambiente, por lo menos desde el lado de la investigación, buscando ir más allá de la educación en salud.

EntreDiversidades. Revista de Ciencias Sociales y Humanidades, Vol. 9, Núm. 1 (18), enero-junio 2022. Páginas: 223-246 ISSN-e: 2007-7610. https://doi.org/10.31644/ED.V9.N1.2022.A09 
Tsing (2004) de este concepto, es decir, como un conjunto de (des)encuentros e interacciones un poco aleatorios y en ocasiones ríspidos que generan algún tipo de entendimiento, aunque sea provisional e inestable.

Los estudios antropológicos han documentado varias de estas fricciones y la misma antropología ha estado imbricada, queriendo o no, en procesos de traducción, pero también de traición. Para ilustrar cómo un diálogo entre conocimientos y prácticas puede conllevar ciertas problemáticas — aun cuando se establezca con las mejores intenciones — presentaré dos ejemplos.

El primero es el caso documentado por Abramowitz (2010) en Liberia de una organización humanitaria enfocada en salud mental que aceptó tomar en cuenta un síndrome de filiación cultural — hoyo en la cabeza - en su práctica médica. Esta organización, trabajando en un contexto posbélico tras sangrientas guerras civiles, tomó con seriedad las manifestaciones de malestar imputadas a "hoyo en la cabeza". Sin embargo, lo que hicieron fue traducirlo a una categoría diagnóstica de la psiquiatría occidental, llamándolo trastorno de estrés postraumático, terminando así por objetivar ese síndrome y ocupándolo como puerta de entrada para tratamientos psiquiátricos. Para la autora, esta operación en realidad muestra la teleología ínsita en muchas intervenciones humanitarias. Un peligro similar se vislumbra cuando nociones "otras" de cuerpo y de emociones (como en el caso huave arriba descrito) se traducen de manera bruta en síntomas, por ejemplo, de "estrés" o "somatización".

El segundo ejemplo retoma la advertencia de Mendenhall y Singer respecto a lo que ocurre cuando ciertos conceptos, como el de sindemia, se difunden y se vuelven hegemónicos produciendo modelos explicativos universales. Para Emily Yates-Doerr incluso un paradigma progresista como el de los determinantes sociales de la salud "puede exacerbar condiciones de desigualdad al priorizar una idea de salud determinada a la distancia por expertos" (2020: 384, traducción propia). ${ }^{16}$ Es este el caso, por ejemplo, de las intervenciones médicas inspiradas por los estudios de epigenética que detectan una relación privilegiada entre "ambiente uterino" y desarrollo de la progenie a lo largo de su ciclo de vida. Estas intervenciones médicas, tan enfocadas en el control de las embarazadas, terminan ocultando las influencias que los fetos y otros actores significativos (miembros de la familia, comunidad) tienen en el bienestar de las propias gestantes (2020: 390). Se trata de un reduccionismo aplicado a problemas biosociales complejos. Esto se acompaña a menudo por tecnificación y estandarización de las soluciones.

Así, mientras que para los huaves la preocupación por la química surge de una conceptualización más amplia de la relación simbiótica entre cuerpo, medioambiente y territorio, el peligro es que desde la ciencia se termine acogiendo esta preocupación, pero se traduzca únicamente en soluciones tecnificadas para disminuir la contaminación ambiental, sin incidir en la defensa del territorio ante proyectos extractivistas.

Frente a estas fricciones, ¿qué papel juega la antropología? Por un lado, las y los antropólogos trabajamos como brókeres, es decir, mediadores entre diversos actores, y nos ocupamos de traducir y hacer entendibles conocimientos diversos. Sin embargo, a menudo esta operación se convierte en

${ }^{16}$ Trad. propia: "Despite its stated goals, however, the social determinants framework may uphold and even exacerbate conditions of inequality by prioritizing and targeting a form of health that has been predetermined by distant experts" (Yates-Doerr, 2020: 384).

EntreDiversidades. Revista de Ciencias Sociales y Humanidades, Vol. 9, Núm. 1 (18), enero-junio 2022. Páginas: $223-246$ ISSN-e: 2007-7610. https://doi.org/10.31644/ED.V9.N1.2022.A09 
hacer digeribles conceptos complejos como sumak kawsay (buen vivir) a la sociedad hegemónica. Este trabajo de traducción es importante pero también peligroso, ya que puede terminar descontextualizando y reproduciendo estructuras de poder (Briggs y Mantini-Briggs, 2016).

Por otra parte, asumir el rol de tricksters, o bufones de corte como lo propone Scheper-Hughes (1990), tiene el potencial de dialogar con los modelos explicativos dominantes, pero a través del desafío, el desacato, incluso la irreverencia. Este juego (serio) permite ser críticos, generar nuevos entendimientos, voltear sentidos, mirar a otras partes y, sobre todo, nunca afianzarse con un modelo. Para Kolb (2015), quien retoma orientaciones teóricas desde el giro ontológico,

es sólo a partir de la equivocación que el antropólogo puede relacionarse y traducir. El equívoco no es algo que pueda (o deba) "superarse" para lograr la relación y la comunicación, pues "el contrario del equívoco no es la verdad, sino lo unívoco, [...] la afirmación de la existencia de un significado único y trascendente" (Viveiros de Castro, 2004: 12). En la teoría de la equivocación controlada, basada en la relacionalidad amerindia, "la equivocación no es aquello que impide la relación, sino eso que la funda e impulsa: una diferencia de perspectiva" (Viveiros de Castro, 2004: 10) (Kolb, 2015: 119).

La aceptación del equívoco y abandono de lo unívoco implica evidentemente "descolonizar ideologías y prácticas de la salud y de la comunicación” (Briggs y Mantini-Briggs, 2016: 265266, traducción propia), ${ }^{17}$ así como "aprender a escuchar modos indígenas de producción del conocimiento en torno a la salud" (2016: 265-266, traducción propia). ${ }^{18}$ No es un camino sencillo y conlleva ciertos riesgos; sin embargo, a estas alturas, queda claro que la comodidad de una ciencia y una práctica médica endogámicas es más perniciosa que útil.

\section{Epílogo}

A lo largo de este artículo me propuse ir más allá de la importante pero ya conocida crítica al paradigma individualista que rige a la biomedicina y que se traduce en políticas y programas de salud orientadas casi exclusivamente al cambio comportamental. Lo que intenté mostrar es la manera en que los enfoques biosociales que se han desarrollado recientemente en diversas disciplinas científicas están desdibujando binomios persistentes, como el de cuerpo/mente y naturaleza/cultura, hecho que presenta algunos puntos de convergencia con varios conocimientos legos (por ejemplo, de los pueblos indígenas) que han sido históricamente subalternizados. Esta subalternización es en primera instancia una injusticia epistémica, pero también una imperdonable pérdida ante los desafíos apremiantes que nos aquejan en la actualidad. Como dije en un principio, la propuesta de "abrazar" en lugar que evitar la fricción que se genera al confrontar e intercambiar conocimientos entre sí tan distantes no puede acompañarse de "respuestas" o "soluciones".

\footnotetext{
${ }^{17}$ Trad. propia: "We have argued that it also requires decolonizing health/communicative ideologies and practices" (Briggs y Mantini-Briggs, 2016: 265-266).

${ }^{18}$ Trad. propia: "Learning to listen to indigenous ways of producing knowledge about health" (Briggs y Mantini-Briggs, 2016: 265-266).
}

EntreDiversidades. Revista de Ciencias Sociales y Humanidades, Vol. 9, Núm. 1 (18), enero-junio 2022. Páginas: 223-246 ISSN-e: 2007-7610. https://doi.org/10.31644/ED.V9.N1.2022.A09 
Tenerlas contradeciría las mismas premisas sobre las cuales se funda esta propuesta de diálogo abierto. Lo que sí puedo atreverme a indicar como escenario futuro es la necesidad de "dar lugar a la indeterminación semiótica-material de la salud" (Yates-Doerr, 2020: 378, traducción propia), ${ }^{19}$ lo cual implicará replantearnos y cuestionar los conceptos que manejamos de manera irreflexiva: cuerpo, enfermedad, individuo. El "no [...] asumir de antemano que sabemos lo que es la diabetes, o lo que es el cuerpo” (Kolb, 2015: v) nos demandará trabajar con y desde las comunidades para encontrar las acciones idóneas para la procuración de lo que determinen sea "bienestar".

\section{Bibliografía citada}

Abramowitz, Sharon Alane (2010). "Trauma and Humanitarian Translation in Liberia: The Tale of Open Mole”. Culture, Medicine and Psychiatry [en línea], 34 (2), pp. 353-379. doi: https://doi.org/10.1007/s11013-010-9172-0 (Consultado el 12 de febrero de 2019).

Beck, Ulrich (1992). Risk Society: Towards a New Modernity. London, United Kingdom: Sage Publications.

Bozada Robles, Lorenzo M. y Bejarano González, Fernando (2006). Los contaminantes orgánicos persistentes en el istmo mexicano. México, D.F., México: Red de Acción sobre Plaguicidas y Alternativas en México, Red Internacional de Eliminación de los COPs, Universidad Istmo Americana, Organización de las Naciones Unidas para el Desarrollo Industrial, Programa de las Naciones Unidas para el Medio Ambiente, Instituto de las Naciones Unidas para Formación Profesional e Investigaciones, Global Environment Facility. Disponible en: https://www.rapam.org/wp-content/uploads/2015/12/Los-Contaminantes-Istmo-Opti. pdf (Consultado el 7 de noviembre de 2021).

Bratman, Gregory N., J. Paul Hamilton y Gretchen C. Daily (2012). "The Impacts of Nature Experience on Human Cognitive Function and Mental Health". Annals of the New York Academy of Sciences [en línea], 1249 (1), pp. 118-136. doi: https://doi.org/10.1111/ j.1749-6632.2011.06400.x (Consultado el 5 de abril de 2021).

Briggs, Charles L. y Mantini-Briggs, Clara (2016). Tell Me Why My Children Died: Rabies, Indigenous Knowledge, and Communicative Justice. Durham, North Carolina, United States of America: Duke University Press.

Cabassa, Leopoldo J., et al. (2008). "Azúcar y Nervios: Explanatory Models and Treatment Experiences of Hispanics with Diabetes and Depression". Social Science \& Medicine [en línea], 66 (12), pp. 2413-2424. doi: https://doi.org/10.1016/j.socscimed.2008.01.054 (Consultado el 31 de octubre de 2012).

Carton de Grammont, Hubert (2009). "La desagrarización del campo mexicano". Convergencia. Revista de Ciencias Sociales [en línea], Núm. 50, pp. 13-55. Disponible en: https://www. redalyc.org/pdf/105/10511169002.pdf (Consultado el 9 de marzo de 2021).

Csordas, Thomas J. (ed.) (1994). Embodiment and Experience: The Existential Ground of Culture and Self. Cambridge, United Kingdom: Cambridge University Press.

\footnotetext{
${ }^{19}$ Trad. propia: “[...] to make space for health's material-semiotic indeterminacy” (Yates-Doerr, 2020: 378).
}

EntreDiversidades. Revista de Ciencias Sociales y Humanidades, Vol. 9, Núm. 1 (18), enero-junio 2022. Páginas: $223-246$ ISSN-e: 2007-7610. https://doi.org/10.31644/ED.V9.N1.2022.A09 
Cuturi, Flavia (1990). "Dalla laguna delle Sirene al mercato dei gamberi". La Ricerca Folklorica, Núm. 21, pp. 61-68. También disponible en: https://doi.org/10.2307/1479351

Damásio, António (1994). El error de Descartes: La razón de las emociones. Santiago de Chile, Chile: Editorial Andres Bello.

Descartes, René (2006). Discurso del método, meditaciones metafísicas, reglas para la dirección del espiritu, principios de filosofía. Estudio introductivo, análisis de las obras y notas al texto por Francisco Larroyo. 21a edición. México, D.F, México: Editorial Porrúa.

Finkler, Kaja (1994). Women in Pain: Gender and Morbidity in Mexico. Philadelphia, Pennsylvania: University of Pennsylvania Press.

Gamlin, Jennie y Berrio, Lina (2020). "Critical Anthropologies of Maternal Health: Theorising from the Field with Mexican Indigenous Communities", en Gamlin, Jennie, et al., (eds.). Critical Medical Anthropology: Perspectives in and from Latin America. London, United Kingdom: UCL Press, pp. 42-68. doi: https://doi.org/10.2307/j.ctv13xprxf.9 (Consultado el 12 de enero de 2021).

Good, Byron J. (1994). Medicine, Rationality, and Experience: An Anthropological Perspective. Cambridge, United Kingdom: Cambridge University Press.

Guerrero Martínez, Fernando (2015). "Concepciones sobre los animales en grupos mayas contemporáneos”. Revista Pueblos y Fronteras digital [en línea], 10 (20), pp. 6-43. doi: https://doi.org/10.22201/cimsur.18704115e.2015.20.31 (Consultado el 9 de marzo de 2021).

Guthman, Julie (2011). Weighing In: Obesity, Food Justice and the Limits of Capitalism. Berkeley y Los Angeles, California, United States of America: University of California Press.

Holmes, Seth M. (2013). Fresh Fruit, Broken Bodies: Migrant Farmworkers in the United States. Berkeley, California, United States of America: University of California Press.

Izquierdo, Carolina (2005). "When 'Health' is Not Enough: Societal, Individual and Biomedical Assessments of Well-being Among the Matsigenka of the Peruvian Amazon". Social Science and Medicine [en línea], 61 (4), pp. 767-783. doi: https://doi.org/10.1016/j. socscimed.2004.08.045 (Consultado el 25 de abril de 2009).

Kelly, Shona J. e Ismail, Mubarak (2015). "Stress and Type 2 Diabetes: A Review of How Stress Contributes to the Development of Type 2 Diabetes". Annual Review of Public Health [en línea], Vol. 36, pp. 441-462. doi: https://doi.org/10.1146/annurevpublhealth-031914-122921 (Consultado el 14 de noviembre de 2015).

Kolb Cadwell, Susana Rebeca (2015). Disyuntivas corporales: hacia una teoría totonaca de la diabetes en Ixtepec, Puebla. Tesis para obtener el grado de Maestría en Antropología, Instituto de Investigaciones Antropológicas, Universidad Nacional Autónoma de México. Disponible en: https://repositorio.unam.mx/contenidos/416332 (Consultado el 5 de octubre de 2021).

Leal Ferreira, Mariana y Lang, Gretchen Chesley (eds.) (2006). Indigenous Peoples and Diabetes: Community Empowerment and Wellness. Durham, North Carolina, United States of America: Carolina Academic Press.

EntreDiversidades. Revista de Ciencias Sociales y Humanidades, Vol. 9, Núm. 1 (18), enero-junio 2022. Páginas: $223-246$ ISSN-e: 2007-7610. https://doi.org/10.31644/ED.V9.N1.2022.A09 
Loza Taylor, Tomas (2017). "Violencia y emociones. Experiencia de la enfermedad en personas con complicaciones crónicas por diabetes mellitus tipo 2 en la localidad de Coatetelco, Municipio de Miacatlán, Estado de Morelos, México". Thule Rivista Italiana di Studi Americanistici [en línea], 42/43, pp. 583-602. Disponible en: http:// www.amerindiano.org/wp-content/plugins/pdfjs-viewer-shortcode/pdfjs/web/viewer. php?file=http://www.amerindiano.org/wp-content/uploads/2019/10/Thule-42-43. pdf\&download=false\&print=false\&openfile=false (Consultado el 12 de enero de 2021).

Maldonato, Mauro y Anzoise, Ilaria (2013). "Homo-Machina Visual Metaphors, Representations of Consciousness and Scientific Thinking”, en Apolloni, Bruno, et al. (eds). Neural Nets and Surroundings. Berlin, Heidelberg, Germany: Springer, pp. 437-451.

Marmot, Michael Gideon, et al. (1978). "Employment Grade and Coronary Heart Disease in British Civil Servants". Journal of Epidemiology and Community Health [en línea], Vol. 32, pp. 244-249. doi: http://dx.doi.org/10.1136/jech.32.4.244 (Consultado el 24 de abril de 2019).

Meloni, Maurizio (2019). Impressionable Biologies: From the Archaeology of Plasticity to the Sociology of Epigenetics. New York, United States of America: Routledge.

Mendenhall, Emily y Jacobs, Elizabeth A. (2012). "Interpersonal Abuse and Depression Among Mexican Immigrant Women with Type 2 Diabetes". Culture, Medicine and Psychiatry [en línea], Vol. 36, pp. 136-153. doi: https://doi.org/10.1007/s11013-011-9240-0 (Consultado el 3 de noviembre de 2012).

Mendenhall, Emily y Singer, Merrill (2019). "The Global Syndemic of Obesity, Undernutrition, and Climate Change”. The Lancet [en línea], 393 (10173), pp. 741-741. doi: https://doi. org/10.1016/S0140-6736(19)30310-1 (Consultado el 12 de marzo de 2019).

Menéndez, Eduardo (2014). "Comentario: De rituales y subjetividades. Reflexiones sobre algunas características de los grupos de Alcohólicos Anónimos”. Desacatos. Revista de Ciencias Sociales [en línea], Núm. 29, pp. 107-120. Disponible en: https://desacatos.ciesas.edu. mx/index.php/Desacatos/article/view/435 (Consultado el 9 de marzo de 2021).

Montesi, Laura (2017a). "Ambivalent food experiences: Healthy eating and food changes in the lives of Ikojts with diabetes". International Review of Social Research [en línea], 7 (2), pp. 99108. doi: https://doi.org/10.1515/irsr-2017-0012 (Consultado el 9 de marzo de 2021).

Montesi, Laura (2017b). "La diabetes como metáfora de vulnerabilidad. El caso de los ikojts de Oaxaca”. Revista Pueblos y fronteras digital [en línea], 12 (23), pp. 46-76. doi: doi: http:// orcid.org/0000-0001-8916-6776 (Consultado el 22 de noviembre de 2021).

Montesi, Laura (2018). “Como Si Nada': Enduring Violence and Diabetes among Rural Women in Southern Mexico”. Medical Anthropology [en línea], 37 (3), pp. 206-220. doi: https:// doi.org/10.1080/01459740.2017.1313253 (Consultado el 8 de marzo de 2021).

Montesi, Laura (pendiente de publicar). "Representaciones sociales y cuidados de la diabetes mellitus tipo 2 por parte de un grupo de jóvenes ikojts en el Istmo de Tehuantepec”, en Sesia, Paola M. y Muñoz Martínez, Rubén (coords.). Politicas globales, vulnerabilidades locales y desigualdades persistentes. La salud de los pueblos indigenas en el sur de México. Ciudad de México, México: Centro de Investigaciones y Estudios Superiores en Antropología Social.

EntreDiversidades. Revista de Ciencias Sociales y Humanidades, Vol. 9, Núm. 1 (18), enero-junio 2022. Páginas: 223-246 ISSN-e: 2007-7610. https://doi.org/10.31644/ED.V9.N1.2022.A09 
Nichter, Mark (2010). "Idioms of Distress Revisited". Culture, Medicine and Psychiatry, Vol. 34, pp. 401-416. doi: https://doi.org/10.1007/s11013-010-9179-6 (Consultado el 11 de febrero de 2019).

Page Pliego, Jaime Tomás (2019). "Memoria, imaginación y miedo en la génesis de la diabetes mellitus. El caso de una mujer guatemalteca”. Revista Pueblos y Fronteras digital [en línea], Vol. 14, pp. 1-25. doi: https://doi.org/10.22201/cimsur.18704115e.2019.v14.433 (Consultado el 8 de marzo de 2021).

Peluffo, Alexandre E. (2015). “The 'Genetic Program': Behind the Genesis of an Influential Metaphor”. Genetics [en línea], 200 (3), pp. 685-696. doi: https://doi.org/10.1534/ genetics.115.178418 (Consultado el 2 de febrero de 2021).

Pickett, Kate E. y Wilkinson, Richard G. (2015). "Income Inequality and Health: A Causal Review”. Social Science and Medicine [en línea], Vol. 128, pp. 316-326. doi: https://doi. org/10.1016/j.socscimed.2014.12.031 (Consultado el 2 de febrero de 2021).

Ramírez Galván Rasgado, Soledad (2020). La formación de la identidad profesional médica entre las y los estudiantes de la facultad de medicina de la Universidad Autónoma Benito Juárez de Oaxaca: Un estudio etnográfico. Tesis para obtener el grado de Maestría en Antropología Social, Centro de Investigaciones y Estudios Superiores en Antropología Social.

Roberts, Elizabeth F.S. y Sanz, Camilo (2018). "Bioethnography: A How-To Guide for the Twenty-First Century”, en Meloni, Maurizio, et al. (eds.). The Palgrave Handbook of Biology and Society. London, United Kingdom: Palgrave Macmillan, pp. 749-775.

Roden, Michael y Shulman, Gerald I. (2019). "The Integrative Biology of Type 2 Diabetes". Nature [en línea], Vol. 576, pp. 51-60. doi: https://doi.org/10.1038/s41586-019-1797-8 (Consultado el 2 de febrero de 2021).

Ruiz, Daniel, et al. (2018). "Disparities in Environmental Exposures to Endocrine-Disrupting Chemicals and Diabetes Risk in Vulnerable Populations”. Diabetes Care [en línea], 41 (1), pp. 193-205. doi: https://doi.org/10.2337/dc16-2765 (Consultado el 7 de abril de 2019).

Saldaña-Tejeda, Abril (2014). "Entre Malinche, Guadalupe y la Llorona: maternidad, cuidados e infancia en México”, en Durin, Séverine, María Eugenia de la O y Santiago Bastos (eds.). Trabajadoras en la sombra. Dimensiones del servicio doméstico latinoamericano. Ciudad de México, México: Centro de Investigaciones y Estudios Superiores en Antropología Social, Escuela de Gobierno y Transformación Pública, Tecnológico de Monterrey, Publicaciones de la Casa Chata, pp. 239-267.

Saldaña-Tejeda, Abril (2018). "Mother's Experiences of Masculinity in the Context of Child Obesity in Mexico". Women's Studies International Forum [en línea], Vol. 70, pp. 39-45. doi: https://doi.org/10.1016/j.wsif.2018.07.013 (Consultado el 3 de febrero de 2021).

Sánchez-Reina, J. Roberto y Brito Fuentes, Carla (2016). “Comunicación de la salud en la campaña 'Chécate, mídete, muévete'. Representaciones y eficacia”. Razón y Palabra, 20 (3_94), pp. 640-656. Disponible en: https://www.revistarazonypalabra.org/index.php/ryp/ article/view/730 (Consultado el 9 de abril de 2019).

EntreDiversidades. Revista de Ciencias Sociales y Humanidades, Vol. 9, Núm. 1 (18), enero-junio 2022. Páginas: 223-246 ISSN-e: 2007-7610. https://doi.org/10.31644/ED.V9.N1.2022.A09 
Scheper-Hughes, Nancy (1990). "Three Propositions for a Critically Applied Medical Anthropology”. Social Science \& Medicine [en línea], 30 (2), pp. 189-197. doi: https:// doi.org/10.1016/0277-9536(90)90079-8 (Consultado el 10 de abril de 2018).

Scheper-Hughes, Nancy y Bourgois, Philippe (2004). Violence in War and Peace: An Anthology. Oxford, United Kingdom: Blackwell.

Secretaría de Salud (2013). Estrategia Nacional para la Prevención y el Control del Sobrepeso, la Obesidad y la Diabetes. México, D.F., México: Secretaría de Salud. Disponible en: https:// www.gob.mx/cms/uploads/attachment/file/276108/estrategia sobrepeso diabetes obesidad.pdf (Consultado el 2 de abril de 2014).

Seeberg, Jens y Meinert, Lotte (2020). "Can Epidemics Be Noncommunicable? Reflections on the Spread of 'Noncommunicable' Diseases”. Medicine Anthropology Theory [en línea], 2 (2), pp. 54-71. doi: https://doi.org/10.17157/mat.2.2.171 (Consultado el 28 de septiembre de 2018).

Shamah-Levy, T., et al. (2020). Encuesta Nacional de Saludy Nutrición 2018. Resultados nacionales [en línea]. Cuernavaca, México: Instituto Nacional de Salud Pública. Disponible en: https://ensanut.insp.mx/encuestas/ensanut2018/doctos/informes/ensanut_2018 informe final.pdf (Consultado el 5 de febrero de 2021).

Signorini, Italo y Tranfo, Luigi (1979). "Enfermedades. Clasificación y terapias", en Signorini, Italo. Los Huaves de San Mateo del Mar. Ideología e instituciones sociales. México D.F., México: Instituto Nacional Indigenista, pp. 215-262.

Swinburn, Boyd, et al. (2019). "The Global Syndemic of Obesity, Undernutrition, and Climate Change: The Lancet Commission report”, The Lancet [en línea], 393 (10173), pp. 791-846. doi: https://doi.org/10.1016/S0140-6736(18)32822-8 (Consultado el 12 de marzo de 2019).

Tsing, Anna Lowenhaupt (2004). Friction: An Ethnography of Global Connection. Princeton, New Jersey, Woodstock, Virginia, United States of America: Princeton University Press.

Vaughan, Megan (2019). "Conceptualising Metabolic Disorder in Southern Africa: Biology, History and Global Health”. BioSocieties [en línea], Vol. 14, pp. 123-142. doi: https:// doi.org/10.1057/s41292-018-0122-3 (Consultado el 18 de febrero de 2021).

Wagner, Julie A., et al. (2011). "Beliefs About Racism and Health Among African American Women With Diabetes: A Qualitative Study”. Journal of the National Medical Association [en línea], 103 (3), pp. 224-233. doi: https://doi.org/10.1016/S0027-9684(15)30298-4 (Consultado el 18 de febrero de 2021).

Yates-Doerr, Emily (2015). The Weight of Obesity. Hunger and Global Health in Postwar Guatemala. Berkeley, California, United States of America: University of California Press.

Yates-Doerr, Emily (2020). "Reworking the Social Determinants of Health: Responding to Material-Semiotic Indeterminacy in Public Health Interventions". Medical Anthropology Quarterly [en línea], 34 (3), pp. 378-397. doi: https://doi.org/10.1111/maq.12586 (Consultado el 16 de julio de 2020).

EntreDiversidades. Revista de Ciencias Sociales y Humanidades, Vol. 9, Núm. 1 (18), enero-junio 2022. Páginas: 223-246 ISSN-e: 2007-7610. https://doi.org/10.31644/ED.V9.N1.2022.A09 